\title{
O DOMÍNIO DA NORMA CULTA DA LÍNGUA PORTUGUESA COMO DETERMINANTE DE INCLUSÃO/EXCLUSÃO NO MUNDO DO TRABALHO
}

\author{
Eneida Maria Erre Araújo \\ Universidade Federal do Maranhão (UFMA) \\ Ilzeni Silva Dias \\ Universidade Federal do Maranhão (UFMA)
}

\section{O DOMÍNIO DA NORMA CULTA DA LÍNGUA PORTUGUESA COMO DETERMINANTE DE INCLUSÃO/EXCLUSÃO NO MUNDO DO TRABALHO}

Resumo: Considerando as mudanças técnico-organizacionais do mundo do trabalho, a presente pesquisa "O domínio da norma culta da língua portuguesa como determinante de inclusão/exclusão no mundo do trabalho" teve como objetivo analisar o domínio da norma culta da língua portuguesa, como fator de inclusão/exclusão nos processos de seleção das empresas privadas de São Luís. Para tanto, faz uma análise da literatura existente, seguida de uma pesquisa de campo, utilizando entrevistas semiestruturadas. Os resultados parciais mostram a importância do conhecimento da norma culta da língua portuguesa e, consequentemente, a constatação de que a língua acaba por excluir o trabalhador do processo produtivo, por meio do domínio da norma culta que aponta como "certa" somente a variante linguística utilizada por determinado grupo social.

Palavras-chave: Mundo do trabalho, Língua Portuguesa, norma culta.

THE DOMAIN OF THE CULT NORM OF PORTUGUESE LANGUAGE AS DETERMINANT IN INCLUSION THE WORLD OF WORK

Abstract: Considering the technical and organizational changes in the workplace, this research " The domain of the cult norm of portuguese language as determinant in inclusion the world of work", aims to analyze the importance attached to knowledge of cultural norms of the Portuguese language, as a determinant of inclusion/exclusion in the selection processes of enterprises in the city of São Luís. Therefore it does an analysis of existing literature, followed by a field survey using structured interviews. Partial results show the importance of knowing the cultural norms of the Portuguese language and therefore the finding that the language turns out to exclude the worker from the production process, through the field of cultural norms that points to "certain" only language used by the variant particular social group.

Keywords: World of work, Portuguese Language, cult norm. 


\section{INTRODUÇÃO}

A presente pesquisa, resultado parcial de uma dissertação de mestrado, empreendeu uma análise sobre o domínio da norma culta ${ }^{1}$ da língua portuguesa, entendida neste estudo como determinante de inclusão/exclusão nos processos de seleção de candidatos a vagas de emprego nas empresas privadas de São Luís, considerando as mudanças técnicoorganizacionais do mundo do trabalho.

A área de estudo, lócus desta pesquisa, compreendeu onze empresas privadas localizadas na zona urbana da cidade de São Luís, no estado do Maranhão. As empresas selecionadas foram de pequeno porte, com dez funcionários, de médio porte com cinquenta funcionários e de grande porte que possuem um número igual ou superior a 100 funcionários em seu quadro funcional.

De cada empresa pesquisada foi possivel entrevistar o profissional (selecionador de pessoas), responsável pelo processo de seleção dos candidatos a vagas de emprego, que serão mencionados no corpo do texto com a letra $S$ seguida do número de ordem de realização das entrevistas em cada empresa e da sigla corresponde ao porte: empresa de pequeno porte (EPP), empresa de médio porte (EMP) e empresa de grande porte (EGP).

Os dados da pesquisa foram obtidos por meio de entrevistas com questões norteadoras, gravadas e transcritas na íntegra, dentre os quais selecionamos recortes para apresentar no estudo, buscando os que melhor permitissem a convergência com o fenômeno estudado.

Convém ressaltarmos que, todas as empresas que participaram da pesquisa se orientam seguindo os preceitos do modelo toyotista de produção, demandando um perfil profissional altamente qualificado para atuar no mundo do trabalho, ou seja, um profissional polivalente, possuidor de novas habilidades cognitivas, competências técnicas e psicológicas, além de domínio de linguagem oral e escrita.

Sabemos que a linguagem tem sua origem ligada à necessidade de comunicação entre os homens. A palavra comunicação provém do verbo latino communicare, que tem como significado pôr em comum. Assim sendo, sua finalidade é pôr em comum ideias, pensamentos, desejos, sentimentos, bem como compartilhar formas de comportamento com 0 objetivo maior de atingir o entendimento entre os homens ou, como afirma Camara Junior (2009, p. 93), trata-se do "Intercâmbio mental entre os homens feito por meio da linguagem."

Para Angeloni (2010, p. 31), "Por meio das comunicações é possível aumentar a sinergia entre as pessoas, diminuindo dúvidas e questionamentos."

É a comunicação que faz com que as pessoas se relacionem, compartilhando experiências e conhecimento de mundo e, ao se relacionarem, são influenciadas, ao mesmo tempo em que se influenciam, transformam a realidade na qual estão inseridas.

As mudanças que vêm ocorrendo nas organizações, consequência da afluência de fatores de natureza sociocultural, econômica e política, apresentam características e exigências dos mais diferentes tipos, dentre as quais se torna importante destacar, para fins de interesse deste estudo, a linguagem verbal, oral ou escrita, que, inserida ou não nos diversos modelos de produção capitalista, tem o objetivo de contribuir para o aumento da produtividade.

A partir desta compreensão, interessa a este estudo apreender a necessidade ou não do uso da linguagem oral e escrita nos diferentes modelos de produção, o que se torna necessário para destacar as principais características dos mesmos.

\section{A LÍNGUA PORTUGUESA E SUA DEMANDA DE COMUNICAÇÃO E EXPRESSÃO NO MUNDO DO TRABALHO A PARTIR DOS MODELOS DE PRODUÇÃO}

Para atender ao propósito desta pesquisa, tomamos como ponto de partida 0 modelo científico de Taylor (1856-1915), ressaltando 0 fato de que a organização do trabalho no modo capitalista tem como foco a produtividade para a lucratividade, então a 
gerência científica se preocupou em focalizar a aplicação dos métodos científicos nos problemas do controle de trabalho, desenvolvendo novos métodos de organização do trabalho nas empresas capitalistas em expansão (TAYLOR, 2009).

Dessa forma, o ponto de partida abordado por Taylor para obter eficiência e maior produtividade do trabalhador foi a proposta de divisão entre 0 trabalho da gerência e o trabalho dos operários, em que, acentuando a divisão técnica do trabalho, já introduzida pelo modo de produção capitalista, materializou a separação entre concepção e execução, que se tornou o princípio chave do sistema de produção taylorista/fordista, visto também como a barreira traçada entre trabalho manual e trabalho intelectual.

Ford (1863-1947) desenvolveu os princípios do taylorismo e acrescentou um caráter inovador, introduzindo a esteira transportadora que se concretizou na linha de montagem, resultando em uma nova maneira de gestão da força de trabalho (FORD, 1954).

A novidade traduzida na linha de montagem orienta o processo de trabalho para dimensões qualitativamente novas, uma vez que a esteira transportadora elimina os tempos mortos do processo de trabalho e os converte em trabalho produtivo.

No que se refere à comunicação, nesse modelo de produção por meio da língua, era bastante escasso, pois a fragmentação, a especialização e o disciplinamento da linha de montagem, próprias do modelo de produção taylorista/fordista impediam maior comunicação no trabalho, uma vez que atrapalhava os níveis de produtividade do trabalhador. Desse modo, só restava ao trabalhador abaixar a cabeça e trabalhar em silêncio.

Cabe ressaltar que esta atividade, tão comum do taylorismo/fordismo, ainda acontece no contexto atual, em empresas que se afirmam modernas, como podemos constatar na fala do selecionador ${ }^{2}$ abaixo:

A experiência do candidato conta muito, e também seu comportamento, porque o cargo que a empresa mais oferece é [...] aqui a gente chama de operacional. $\mathrm{Na}$ verdade, é o peão mesmo. Os operários que lidam diretamente com 0 processo produtivo, por sermos uma indústria de móveis projetados, o nível dos peões, o nível é bem baixo. Eles vão lidar mesmo é com o serviço braçal, pegar no pesado, entendeu? Nesse caso, quanto mais trabalharem calado, melhor porque assim produzem mais em pouco tempo, porque a maioria deles vai mesmo é trabalhar na fabricação dos móveis, então precisamos que se comportem se concentrem de forma a fazer seu serviço em silêncio. (Informação verbal) ${ }^{3}$.

Podemos ressaltar, a partir do depoimento acima que, embora no discurso dos funcionários, a empresa seja considerada moderna, na prática trata--se de uma organização que ainda se fundamenta no modelo taylorista/fordista, tendo em vista que no modelo de produção toyotista, como veremos adiante, o processo produtivo é orientado pelos próprios trabalhadores a partir de informações verbais, utilizando a língua portuguesa como meio de comunicação.

O modelo japonês, também chamado de ohnismo ou toyotismo, apresenta como um de seus principais objetivos criar produtos diferenciados em escalas menores e, para tanto, Onho (1912-1990), engenheiro-chefe da fábrica toyota, transformou-a em uma fábrica com uma quantidade mínima de trabalhadores e com capacidade de reduzir ou aumentar a produção conforme a demanda.

Concomitante a isso, incentivava o controle direto sobre os funcionários subordinados e motivava a transparência dos padrões de operação para que as chefias pudessem visualizar e tomar conhecimento dos problemas existentes na produção (CORIAT, 1994).

Para tanto, precisavam se comunicar, e a maneira de melhor fazê-lo era utilizando a língua para questionar, analisar, trocar informações e elaborar sugestões que garantissem aperfeiçoamento e melhoria da qualidade do trabalho e aumento da produtividade, com menores custos e tempo de trabalho menor para a empresa.

De acordo com Ana Elisa Moreira Ferreira e Vivian Oliveira dos Santos Silva (2002), consultoras da www.calltocall.com.br, 
site projetado para oferecer serviços de consultoria a empresas,

O mundo atual exige, cada vez mais, profissionais capacitados e com habilidades em diferentes áreas de competência. A competência comunicativa; conhecimento, habilidade, atitude e capacidade do indivíduo de assimilar, organizar e transmitir informações com eficácia, refletindo no relacionamento com 0 interlocutor, é um dos pré-requisitos mais observados no mundo empresarial.

Depreendemos daí, a importância do trabalho em equipe e da comunicação no toyotismo, em que o trabalhador precisa ter uma visão de todo o processo de trabalho na sequência de montagem e construção de um determinado item do produto, bem como participar, trocar ideias, informações e conhecimentos no processo produtivo.

Para tanto, o processo de comunicação exige uma interação, um comum acordo sobre determinada ideia ou pensamento, e esta comunicação, como já foi mencionado, faz-se por intermédio de uma linguagem verbal, que em nosso estudo se trata da língua portuguesa.

Assim, as imensas peculiaridades que caracterizam o trabalho na contemporaneidade convergem para o fato de que, além de toda a tecnificação que marca o mundo do trabalho, também as capacidades humanas, dentre elas a linguagem, encontram-se subjugadas à lógica do sistema de sociedade vigente, contribuindo para a lógica do valor, do capital e da extração de mais-valia.

Quando reconhecemos a subjugação da linguagem ao capital, referimo-nos ao fato de que o domínio da norma culta da língua portuguesa é exigido como competência para adentrar no mundo do trabalho, ou seja, o uso da norma culta da língua, segundo os preceitos da gramática, configurada como a maneira certa de comunicação, como podemos constatar na fala do selecionador da empresa, abaixo:

No contexto que trabalhamos hoje, é fundamental que 0 candidato apresente o mínimo de conhecimento da língua portuguesa, sabendo pelo menos a concordância entre os nomes e os verbos no momento de elaborar suas falas porque isso facilita o entendimento da mensagem que ele quer passar. Nossa empresa tem uma imagem e precisamos selecionar pessoas que compartilhem da missão com a qual trabalhamos. Então não dá pra aceitar um candidato que não saiba se comunicar usando uma boa linguagem. (Informação verbal) ${ }^{4}$.

Percebemos a língua, sobretudo, como determinante de inclusão, permitindo ao trabalhador o acesso ao cargo; com o fim de contribuir essencialmente para 0 bom funcionamento organizacional e melhores resultados produtivos.

Nessa perspectiva, o bom desempenho linguístico do candidato está relacionado ao domínio da língua portuguesa, clareza e correção gramatical, ou seja, ao conhecimento da norma culta da língua portuguesa, conhecimento esse ligado à rigidez das regras gramaticais, entendidas, segundo Bagno (2003, p. 20)

[...] gramática entendida como uma série de regras de funcionamento mecânico que devem ser seguidas à risca para dar um resultado perfeito e admissivel.

Desse modo, entendemos que valorizar somente uma variedade da língua é considerar ela, e somente ela, a norma culta, como a mais importante, desconsiderando outros aspectos, como os fatores extralinguísticos (de origem geográfica, status econômico, grau de escolarização, idade etc) também importantes, envolvidos no processo de comunicação, pois como afirma Bagno (2007, p. 48),

[... toda e qualquer variedade
linguística é plenamente funcional,
oferece todos os recursos
necessários para que seus falantes
interajam socialmente.

Diante desse fato, podemos inferir que não é o domínio da norma culta da língua portuguesa que atenderá à comunicabilidade, mas a interação é que fará com que a linguagem seja comunicativa. Toda ação humana tem como ponto de partida a interação, portanto, como destaca Bakhtin 
(2010, p. 117, grifo do autor), a palavra constitui o produto da interação do locutor e do ouvinte, ou melhor,

[...] toda palavra comporta duas faces.

Ela é determinada tanto pelo fato de que procede de alguém, como pelo fato de que se dirige para alguém. Ela constitui justamente 0 produto da interação do locutor e do ouvinte. Toda palavra serve de expressão de um em relação ao outro.

Desse ponto de vista, é importante colocar a comunicação como um fenômeno que vai além da transferência de mensagens, pois percebemos que 0 processo de comunicação nas organizações incorre bastante sobre a funcionalidade, em que grande parte de atenção é dada aos instrumentos ou ferramentas de comunicação.

\section{DA PRÁTICA DO SILÊNCIO À PRÁTICA DA COMUNICAÇÃO: a linguagem verbal, oral} e escrita como determinante de inclusão/exclusão no mundo do trabalho

Ao compartilharmos da ideia de que a linguagem verbal, oral e escrita é considerada fator de produtividade, sob os moldes do modelo de produção toyotista, buscamos apreender na pesquisa empírica informações que desvelassem as demandas da língua portuguesa nos processos de seleção das empresas privadas maranhenses.

A comunicação verbal é associada às palavras expressas, por meio da linguagem escrita ou oral. Assim, a língua é fundamentalmente, segundo Saussure (2006, p. 17), um instrumento de comunicação, sendo, neste caso, vista como um sistema ou

[...] um produto social da faculdade
da linguagem e um conjunto de
convenções necessárias, adotadas
pelo corpo social, para permitir o
exercício dessa faculdade nos
indivíduos.

Já Orlandi (1992) aponta que a língua é feita de discursos ${ }^{5}$, os quais constituem os sentidos da comunicação. Refere-se ao silêncio como parte indissociável de qualquer discurso, destacando que o sentido somente é obtido através de silenciamentos.
Assim, o silêncio pode ser

[...] aquilo que é preciso não dizer para que o texto se feche e, em conseqüência, seja coerente, não contraditório, capaz de unidade, de progressão em uma direção dada, tendo conseqüências discursivas conformes. (ORLANDI, 1992, p. 106).

Dentre as variedades de silêncio apresentadas pela autora, em sua obra As formas do silêncio, o silêncio, a não concretização da fala, do evento físico foi um fenômeno bastante presente no taylorismo/fordismo, pois, como já dito, os trabalhadores nesse modelo de produção exerciam suas atividades em silêncio.

No que concerne à linguagem, podemos afirmar que atualmente seu conceito, de acordo com Cunha apud Martelotta (2008, p. 15-16), "[...] é mais comumente empregado para referir-se a qualquer processo de comunicação.", sendo também apontada como uma habilidade, ou seja, "[...] a capacidade que apenas os seres humanos possuem de se comunicar por meio de línguas."

Portanto, os pressupostos teóricos que mais se aproximam do interesse de nosso estudo requerem uma análise da linguagem sob o ponto de vista da sociolinguística, que

[...] veio mostrar que toda língua muda e varia, isto é, muda com o tempo e varia no espaço, além de variar também de acordo com a situação social do falante. (BAGNO, 2007, p. 43, grifos do autor).

$\mathrm{Na}$ fase de análise, realizamos os recortes, elegendo-os e agrupando as ideias e expressões contidas, a partir de algumas questões norteadoras da pesquisa. Desse modo, quando questionamos Qual o Perfil profissional contemplado pelas empresas privadas maranhenses? Observamos que as falas dos selecionadores representam a homogeneidade de um mesmo discurso que vem ao encontro das novas concepções acerca do papel dos trabalhadores nas organizações que passaram a ser vistos como colaboradores e parceiros da empresa.

Percebemos ainda que, de acordo com as mudanças que as organizações vêm sofrendo desde a década de 1980, resultado da 
globalização da economia, evolução das comunicações, desenvolvimento tecnológico e competitividade, os trabalhadores passaram a ser reconhecidos como fornecedores de conhecimento, habilidades e capacidade, como podemos aferir das falas dos selecionadores abaixo:

Uma habilidade prioritária para 0 candidato ingressar na carreira é que ele precisa ser proativo. [...] É importante para nossa empresa a opinião do time com 0 qual trabalhamos, por isso primamos por um ambiente onde todos possam participar e se sentir bem à vontade para dar suas opiniões em relação ao melhor desenvolvimento de suas tarefas no trabalho porque a partir do momento que se sentir bem ele vai trabalhar melhor. (Informação verbal) ${ }^{6}$.

É fundamental para o desenvolvimento e crescimento profissional do candidato que ele demonstre domínio da língua portuguesa, clareza na hora de falar. Isso demonstra que ele é bem qualificado. (Informação verbal) ${ }^{7}$.

Se o candidato se apresenta como um bom profissional, com um excelente currículo, com um perfil bem qualificado, e com experiência e diz "o que tem pra mim fazer nesse setor é supervisionar como cada técnico desenvolve os procedimentos" aí não dá, não tem como considerar uma fala assim, ainda mais vinda de um profissional que se diz muito bem qualificado, então assim, a gente corta mesmo. (Informação verbal) ${ }^{8}$.

Depreendemos das falas dos entrevistados que, palavras como colaborador, time, qualificação profissional, líder, proativo e talento foram bastante recorrentes, sendo que todas elas concorrem para constatarmos características marcantes do discurso empresarial no contexto do sistema de produção flexível, em que os empregados são tratados como parceiros da organização, o que denota, na verdade, uma estratégia planejada da empresa em obter desse trabalhador maior engajamento em prol dos objetivos organizacionais.
A relação do domínio da norma culta da língua portuguesa com a qualificação profissional nos permite constatar que sob 0 ponto de vista dos selecionadores, é de grande importância que 0 candidato detenha tal domínio, pois, segundo eles, fazer bom uso da língua, apresentar boa expressividade oral e escrita, saber se comunicar em público e com a equipe de trabalho, é muito importante para a empresa e um diferencial valiosíssimo para o profissional que busca a inclusão e permanência, com sucesso no mercado de trabalho.

Reinteramos, baseados em Travaglia (2009) que a norma culta constitui o português correto e o domínio dessa norma, o conhecimento das regras gramaticais no uso da língua confere ao candidato maiores possibilidades de inclusão no mundo do trabalho.

No que se refere a $O$ que a empresa analisa durante o processo de seleção, é grande a preocupação das empresas em relação à questão de o candidato apresentar uma boa comunicação, boa capacidade de bem falar e bem escrever, mas atrelado a isso existem outros aspectos que são bastante considerados, como a experiência do candidato e o seu comportamento durante o processo de seleção, como podemos conferir a partir das falas dos selecionadores abaixo,

A base de triagem da minha empresa busca um público que já tem experiência e o que não tem. Hoje temos orgulho em falar que a nossa empresa desenvolve e capacita as pessoas. (Informação verbal) .

O perfil do candidato almejado pela empresa, é que o mesmo tenha uma boa comunicação, que saiba expor suas ideias de forma clara se expressar bem e de forma objetiva. Uma linguagem certa torna-se essencial para ocupar uma vaga. (Informação verbal) $)^{10}$.

A aparência conta muito, a forma como a pessoa se comporta, como se veste, se penteia também. É claro que a gente erra na seleção, a gente se engana na hora de escolher 0 melhor candidato. Então o teste verdadeiro é o trabalho, é colocar a 
pessoa para trabalhar. Nós investimos no funcionário e treinamos ele dentro daquilo que a empresa quer. (Informação verbal) ${ }^{11}$.

Para os selecionadores, além do comportamento, a facilidade que o candidato apresenta em se comunicar conta bastante. Dentre as qualificações exigidas está 0 emprego adequado da língua durante 0 processo de seleção.

Foi possivel perceber que os candidatos são incluídos ou excluídos levando em consideração 0 falar e 0 escrever bem baseados somente na norma culta; isso significa que ele recebe sua avaliação baseada numa maneira de conceber a língua de forma homogênea, uniforme, sendo ela vista acima das diferenças regionais e sociais. Todavia, como já dito, as variações do português são muitas: regionais, sociais, culturais, históricas, idade etc. Sendo assim, temos uma língua que apresenta variações em dimensões orais e escritas.

No que diz respeito à análise do currículo do candidato e aspectos considerados mais relevantes, percebemos uma incidência considerável por parte dos entrevistados em apontar que um dos aspectos mais observados e que estabelecem parâmetros para a seleção é a escrita correta, sendo apontada como o bom uso da língua portuguesa.

Os selecionadores se referem em diversos momentos a construções como: falar e escrever bem, uso da língua adequado ao padrão; noção de certo e errado, correção gramatical, entre outras expressões que vêm ao encontro de que ter o domínio da língua é o mesmo que saber norma culta. Não há por parte dos selecionadores uma preocupação em explicitar o que está sendo entendido como domínio da língua e, quando isso acontece, a explicação fica restrita à questão ortográfica.

Todos são importantes porque a gente faz a triagem dos candidatos pelo currículo. No primeiro contato se observa foto [...] se a pessoa se apresenta de uma maneira vulgar então a gente já evita [...] mas a gente observa muito a escrita correta. Ontem mesmo eu estava selecionando os candidatos pra fazer entrevista pelos currículos e em um deles, a pessoa tinha que escrever incompleto e escreveu incompleto com $\mathrm{m}$ (imcompleto) e isso me chamou muita atenção, eu circulei [...] Mas, enfim eu o chamei, mas confesso que já o analisei de uma maneira diferente. (Informação verbal) ${ }^{12}$.

É muito importante. É todo um conjunto que chama a atenção, e não só uma qualidade específica, mas a escrita correta chama mais a atenção, [...] se você pega um currículo bem feito, organizado, objetivo, bem escrito vai contar bastante, vai fazer diferença. [...] Pra você ter uma ideia, um dia desses apareceu um currículo escrito "bauconista" com "u", esse eu nem chamei. Então assim a forma da escrita é muito importante nessa hora, faz diferença porque o currículo escolhido é aquele com menos erros de português. (Informação verbal) ${ }^{13}$.

Para os selecionadores, usar a língua com clareza, objetividade, correção, concisão e coerência, é uma vantagem competitiva e por isso ela está presente nas diversas etapas do processo seletivo das empresas, pois é por meio dela que o candidato pode influenciar de maneira positiva no momento de ser avaliado.

Convém destacar que, em relação à expressão domínio da língua, concordamos com Travaglia (2009, p.17) quando apresenta o conceito de competência comunicativa como "[...] a capacidade do usuário de empregar adequadamente a língua nas diversas situações de comunicação.", ou seja, dominar a língua é utilizá-la de acordo com cada contexto de comunicação e não somente seguindo as normas de bom uso da língua, configurando 0 falar e escrever bem.

Interessante perceber que, no contexto de trabalho atual, em que é exigido trabalhadores polivalentes, os conhecimentos relativos a uma profissão, por exemplo, não são relevantes, não são suficientes; o que começa a ser priorizado desde a primeira etapa do processo de seleção é a boa comunicação, a força de vontade para aprender, a participação e disposição para dar sugestões, a organização, as relações interpessoais do candidato, ou seja, características descritas, segundo Leite (2003, p. 14) como: 
[...] uma nova síndrome de requisitos, marcada por atributos atitudinais e não apenas cognitivos, com destaque para a responsabilidade e a postura cooperativa (seja em relação aos colegas, seja em relação à empresa), para o engajamento ou envolvimento com os objetivos gerenciais, para a disposição a continuar aprendendo, a se adaptar a novas situações, a ter iniciativa e a solucionar problemas.

Com relação ao teste escrito, a redação é considerada uma etapa em que é possível constatar o uso correto da língua portuguesa pelo candidato. A norma culta da língua está associada à escrita, ao modelo considerado socialmente correto, e pelo que pudemos depreender das falas dos entrevistados, é a concebida como certa e acaba sendo um dos pontos determinantes do processo de seleção, e responsável pela aceitação e boa impressão do candidato.

Percebemos que a ideia de regras a serem seguidas está implícita na maioria dos relatos, validando o ensino de metalinguagem ${ }^{14}$ e a gramática ${ }^{15}$ como objeto de ensino.

A tradição gramatical normativa é geralmente a referência para um bom perfil profissional. Entendemos tratar-se de uma referência que vem sempre associada ao caráter coercitivo da gramática, que desconsidera outras formas da língua e determina, a partir dos modelos tidos como corretos, o que é aceito ou não na língua portuguesa.

Normalmente aqui na empresa não trabalhamos com a redação durante a seleção, mas quando há um empate técnico entre os candidatos, é a redação, com menos erros de ortografia, de acentuação e de concordância, uma redação com uma linguagem boa, bem desenvolvida, que garante qual dos candidatos fica com a vaga. (Informação verbal) ${ }^{16}$.

Na escrita da pessoa, eu já consigo observar o nível intelectual, a organização [...] Eu mesma corrijo, realmente dá trabalho, mas eu verifico todas as redações desde, por exemplo, ideia com acento ou sem acento, eu observo se ele sabe colocar o ponto parágrafo, se a pessoa escreve problema, fico muito triste quando um engenheiro escreve poblema, mas acontece, então é impossivel eu aprovar alguém que tenha esse tipo de escrita. Por quê? Porque ele vai tratar diretamente com a alta gerência da empresa, vai passar e-mails, vai elaborar avisos, pauta de reunião, vai tratar com órgãos públicos, ele vai ter subordinado, ele vai ter líderes, então se não escreve corretamente, pra mim, mesmo se ele tiver a bagagem técnica de conhecimento realmente ele não passa no crivo. (Informação verbal) ${ }^{17}$.

Pelo exposto, fica claro que o desafio dos candidatos é saber empregar os vocábulos certos, a concordância, a regência e a pontuação adequadas para expressar as ideias de maneira clara, concisa e criativa, nas formas escrita ou oral, de acordo com a gramática normativa, ou seja, utilizar a língua apenas em sua variedade culta.

Quando se trata de entrevistas para todos os cargos, pelo exposto na fala dos selecionadores, a parte da entrevista oral consta para todos os cargos, tanto nas EPP quanto nas EMP e nas EGP.

Entretanto, quando a seleção de pessoas é para cargos mais elevados, tanto nas EMP como nas EGP, a equipe se torna fundamental, no momento da escolha, em que cada profissional analisa e discute os aspectos considerados determinantes para que 0 candidato preencha a vaga de emprego.

Os selecionadores apontam que, dependendo dos erros, o candidato é aceito ou não na empresa. Os erros mais graves, segundo eles, são aqueles mais perceptíveis, que chamam a atenção (ortografia, troca de letras, concordâncias explícitas). Já os erros mais sutis são aqueles que não são percebidos imediatamente (erros de sintaxe e concordâncias implícitas).

Existe certa tolerância com os chamados erros da língua portuguesa, dependendo da função que será exercida pelo trabalhador. Se ele vai exercer uma tarefa braçal, que não exige o contato direto com o cliente há uma evidência em se tolerar mais esse tipo de erro. Já para os cargos considerados mais intelectualizados, melhores, que exigem um 
contato maior com o público, com alguma liderança, com a equipe de trabalho, ficou evidente que a tolerância não existe.

O cargo aqui é somente 0 de vendedor, e além do currículo a entrevista é fundamental porque como vendedor ele vai precisar se comunicar não só com os clientes, mas com a equipe da empresa (os outros vendedores e seu chefe), interpretar um recado escrito deixado de um turno pra outro, comunicados de encontros e congressos, e-mail de editoras com as quais a gente trabalha, sinopse de livros, anotar pedidos de clientes, preparar uma licitação. (Informação verbal) ${ }^{18}$.

Olha se o empregado vai ficar na parte da oficina mecânica, não tem problema se ele fala errado porque ele não vai atender clientes, ele vai cuidar dos carros, ele não vai vender carros, então ele só tem que saber a parte técnica do trabalho não precisa falar bem. (Informação verbal) ${ }^{19}$.

Não é levada em consideração a existência de uma gramática internalizada - o conjunto de regras que o falante domina e que permite o uso normal da língua em situações de interação comunicativa (POSSENTI, 1996).

Quando questionados sobre $A$ valorização, durante a entrevista oral, da expressão, de acordo com as normas da gramática, utilizada pelo candidato, os selecionadores explicaram que a entrevista oral é uma parte importante, pois é durante esta etapa que o selecionador vai apreender o perfil do candidato; é a partir de sua expressão oral que serão avaliados seus saberes em relação à língua portuguesa.

Um ponto importante observado é que a oralidade só veio a ser exigida nos processos de seleção na realidade dos processos atuais, juntamente com as transformações do mundo do trabalho, e nesse contexto ela traz uma carga significativa na etapa da entrevista, uma vez que o candidato, ao expressar seus conhecimentos através da oralidade, é também avaliado na sua postura, comportamento e atitude.

De acordo com os selecionadores é através da oralidade que 0 candidato revela 0 seu perfil no momento da entrevista, em especial seu domínio da norma culta que é exigido no momento da entrevista. Essa valorização da norma culta durante todo o processo de seleção, inclusive na modalidade oral da língua tem revelado a importância que as empresas têm dado a certa concepção de linguagem no processo seletivo que se trata justamente da concepção que tem a língua como instrumento de comunicação (TRAVAGLIA, 2009).

De modo geral, a oralidade é mais espontânea que a escrita e tem o poder da comunicação imediata, enriquecido pela pronúncia, pela entonação, pelo timbre da voz, entre outros aspectos. Portanto, a forma como se processa 0 ato da comunicação através da palavra falada muitas vezes determina 0 sucesso ou o fracasso de um profissional, na medida em que o emprego das palavras na manifestação das ideias, complementado pelo tom de voz e pelo modo de se vestir, fica registrado como sua marca na sociedade em que vive.

Percebemos que existe por parte dos selecionadores uma supervalorização da variedade linguística vinculada ao grupo economicamente privilegiado, que detém 0 poder social, o jogo econômico e, por isso, acaba dominando os outros grupos. Esta variedade linguística, a norma culta, também está ligada à tradição escrita, concebida como a maneira correta de escrever e falar.

As falas abaixo são reveladoras do modo como as empresas se comportam em relação à diversidade linguística.

Sim, com certeza, é o mínimo, o candidato não precisa falar formalmente o tempo todo, mas ele precisa se expressar bem, se fazer entender, porque como somos uma empresa em que a maior parte de nossos clientes ou são estudantes de direitos, ou já são profissionais formados, fazendo concurso, estudando causas relacionadas a seu trabalho como advogado, [...] Então são pessoas com um conhecimento mais elaborado, digamos assim, de uma classe social maior, em que o vendedor precisar saber o que vai 
falar e como falar, se comportar, sem ser inconveniente, e nem falar errado. (Informação verbal) ${ }^{20}$.

Então se ele se apresenta como um profissional que dispõe de um excelente currículo, com um perfil bem qualificado, e com experiência e diz "o que tem pra mim fazer nesse setor é supervisionar da melhor maneira possível como cada técnico desenvolve os procedimentos" aí não dá, não tem como não considerar uma fala como essa vinda de um profissional que se diz muito bem qualificado e quando chega pra se expressar com frases, que você utiliza facilmente no dia a dia e comente um erro assim, aí não dá pra não levar em consideração. (Informação verbal) ${ }^{21}$.

Percebemos que por não dominarem a norma culta da língua portuguesa, os falantes são excluídos nesta etapa do processo de seleção, e considerados, muitas vezes, inaptos para o exercício de determinadas funções.

0 uso linguístico próprio de cada candidato e adequado à situação comunicativa não é valorizado neste momento da seleção, o que faz com que as classes menos favorecidas, que apresentam o não domínio da norma culta em sua expressão oral, sejam impedidas de acessar melhores postos na hierarquia do trabalho dentro das empresas pesquisadas.

Em função disso, resta aos trabalhadores que não dominam a norma culta da língua exercerem funções de menor valor social, executar trabalhos operacionais, recebendo por isso uma remuneração inferior. Já os falantes que apresentam domínio da norma culta da língua exercem funções mais intelectualizadas e por isso recebem remuneração maior, o que torna evidente 0 valor de mercadoria da língua e o valor que, em função dela, é atribuído ao profissional.

Em relação ao Uso da língua portuguesa com clareza e fluência como fator facilitador para uma melhor comunicação para que o candidato desempenhe melhor sua função na empresa, todos os selecionadores foram unânimes em admitir que o uso da norma culta da língua portuguesa ajuda o trabalhador a desenvolver melhor sua função na empresa.
Nesse sentido, a expressão domínio da língua foi utilizada com bastante frequência, bem como eficiência e eficácia na comunicação.

O candidato não precisa ter domínio de todas as regras da gramática, mas ele precisa ser objetivo com as palavras. Pra gente conta muito a objetividade do candidato, 0 desembaraço com as palavras, ao responder as perguntas. A forma como ele se comunica, se expressa, se tem clareza no que diz, fluência, demonstra se ele tem agilidade com as palavras, e isso vai ajudar aqui no trabalho. Geralmente um candidato que se expressa bem, com eficiência, com precisão, mostra que para desenvolver seu trabalho ele também será eficiente. É terrível, durante uma entrevista, o candidato ficar dando voltas, sem conseguir explicar o que quer, responder o que precisa. Eu não tenho como ficar numa entrevista com ele 3 ou 4 horas, eu não disponho desse tempo. Pela maneira como ele se expressa eu sei se ele vai ter facilidade de compreender 0 que foi dito, a ordem transmitida, as necessidades da empresa. (Informação verbal) ${ }^{22}$.

A valorização da norma culta da língua portuguesa, nesses enunciados, mostra a importância que ela tem no processo seletivo. Pelo exposto, fica claro que o desafio dos candidatos é saber empregar os vocábulos certos, a concordância, a regência e a pontuação adequadas para expressar as ideias de maneira clara, concisa e criativa, nas formas escrita ou oral, de acordo com a gramática normativa.

Nessa perspectiva, é a concepção de linguagem que tem a língua como instrumento de comunicação que é determinante para a inclusão do candidato, sendo estabelecida a relação língua versus desempenho profissional.

Quando questionados se Muitos candidatos são reprovados em função de demonstrarem o não domínio da língua portuguesa, os selecionadores relatam que 0 domínio da língua portuguesa é de suma importância, e que em alguns casos os candidatos não são aceitos para o cargo, pois o que é priorizado são as situações comunicativas mais formais. 
Nesse sentido, buscamos compreender, por meio das falas dos selecionadores como eles se posicionam diante da questão e quais as consequências disso para o trabalhador.

Os selecionadores percebem a língua como instituída socialmente e carregada de representações simbólicas (SOARES, 2008) em que é apontado um padrão e, consequentemente, um conjunto de regras e normas a serem seguidas (papel da gramática normativa) para representar o bom uso da língua, tornando-se motivo de exclusão daqueles que não demonstrarem esse domínio.

Destacamos abaixo alguns recortes das falas dos selecionadores,

Olha se o currículo (escrito) tiver muitos erros de português então eu nem chamo esse candidato, porque passa logo a impressão de que ele não lê, não tem costume de escrever, então fica difícil um perfil assim para uma livraria porque compromete a imagem da nossa empresa. (Informação verbal) ${ }^{23}$.

A maneira dele falar é importante, demonstra que ele tem conhecimento do que tá falando sobre o produto e o serviço que tá vendendo. É mais fácil o funcionário fechar uma venda se ele sabe falar bem, e também no tratamento que ele vai dispensar pro cliente. Nesse tratamento ele não é só o funcionário da empresa, ele é a empresa, então é importante que a imagem da empresa seja conservada e o funcionário faz a imagem da empresa. (Informação verbal) ${ }^{24}$.

O falar bem, segundo os selecionadores, está intrinsecamente relacionado ao domínio da leitura e da escrita em língua portuguesa, trata-se de se expressar de modo claro, correto, seguindo o uso da norma culta da língua. Somente essa modalidade aponta, segundo eles, para a construção de uma imagem positiva da empresa.

É interessante notar que sob o ponto de vista dos selecionadores, o trabalhador é a empresa. Observamos claramente a ideia contínua de que a boa imagem da empresa está vinculada ao desempenho do trabalhador em relação ao uso da língua.

A maneira de bem falar aludida pelos selecionadores é a utilização da língua portuguesa difundida nas escolas, e entre as classes dominantes, é a língua que adota como referencial a norma culta da língua, o português culto. Aquele português sistemático que segue normas e regras gramaticais.

Os enunciados analisados mostram a posição ocupada pela língua portuguesa nos processos de seleção das empresas privadas, revelando que a imagem da empresa em seu setor de atuação depende da forma como os trabalhadores utilizam a língua portuguesa.

\section{CONCLUSÃO}

A principal motivação de nosso estudo foi a necessidade de analisar a língua portuguesa nos processos de seleção de empresas privadas, da cidade de São Luís, verificando a correlação do domínio da norma culta da língua como determinante de inclusão/exclusão, diante das mudanças técnico-organizacionais do mundo do trabalho.

Consideramos importante ressaltar que as transformações técnico-organizacionais, que impactaram o mundo do trabalho nos últimos anos do século XX, sob a égide do toyotismo, demandaram um novo conteúdo de trabalho e também um novo trabalhador.

Na composição desse novo trabalhador, a linguagem verbal, oral e escrita destaca-se, pela via de comunicação, como componente essencial no sistema de produção flexível, considerada fator de produtividade nas empresas, pois, de acordo com os especialistas, ela desempenha um papel extremamente relevante nas relações de trabalho e é uma das condições exigidas para a inclusão/exclusão do trabalhador no mundo do trabalho.

A partir das análises empreendidas em torno de como as empresas estão atuando em relação à língua portuguesa em seus processos de seleção de pessoas para compor seu quadro funcional, constatamos que a imagem consolidada da língua no mundo empresarial maranhense é a língua compreendida como norma culta, como falar e escrever corretamente. Percebemos que há 
uma tendência geral, nos relatos dos selecionadores de pessoas das empresas pesquisadas, em reconhecer na língua portuguesa uma unicidade e uma invariabilidade, como se somente uma, a norma culta da língua utilizada pelas instituições oficiais e pelos órgãos do poder, fosse digna e legítima. Tal realidade linguística, para os selecionadores, encontra-se tão determinada pela visão da norma culta que eles trazem em suas falas a homogeneização da língua, marcada de forma recorrente pela preocupação com a correção gramatical, com o certo e o errado.

Os selecionadores exprimem em suas falas argumentos que produzem uma justificativa para a valorização atribuída ao domínio da norma culta da língua portuguesa, sendo seu não domínio o argumento que justifica a exclusão do trabalhador do processo, visto que essa é uma exigência para o exercício das funções exercidas pelos trabalhadores no contexto do toyotismo, principalmente, as funções mais intelectualizadas. Ficou claro que quem se expressa com desenvoltura e correção gramatical ganha espaço em detrimento daquele que não demonstrar a mesma competência linguística.

Desse modo, o que se constatou, nesta pesquisa, é a importância de se conhecer a língua portuguesa e suas variedades, destacando a norma culta como aquela que faz a diferença numa seleção para aquisição de uma vaga no mundo do trabalho, pois um fator que orientou significativamente a seleção foi perceber, nas práticas discursivas dos selecionadores, que o domínio da norma culta da língua portuguesa, na feição oral ou escrita, mesmo que sutilmente, determina a exclusão do trabalhador do mundo de trabalho, uma vez que a perspectiva pensada pelas empresas maranhenses em relação à língua portuguesa, diante do atual sistema produtivo, segue pela via do domínio da norma culta da língua considerada como a certa para se comunicar.
Vale ressaltar que, diante da realidade constatada em nossa pesquisa, fazem-se necessários maiores investimentos em estudos linguísticos, ou seja, sociolinguísticos, no sentido de desmistificar mitos antigos, conceitos conservadores que ainda se fazem presentes no contexto de uma sociedade heterogênea como a nossa.

Sob o ponto de vista linguístico, todas as variedades linguísticas se equivalem, todas têm sua lógica de funcionamento, todas obedecem a regras gramaticais que podem ser descritas e explicadas. Assim, compartilhamos com a ideia de que a língua não pode servir para a exclusão, nem deve ser compreendida de forma dissociada das condições históricas e sociais em que ocorre, pois como afirma Bagno (2007, p. 14), "[...] o modo e a razão de ser de cada discurso só se revelam se integrados em seu heterogêneo contexto cultural de origem."

Entendemos que a contribuição maior que nosso estudo oferece é, mais uma vez, trazer para o cenário acadêmico de debates linguísticos a discussão em torno do uso da norma culta da língua portuguesa pelo trabalhador brasileiro numa etapa singular de sua vida profissional, que é o processo de inclusão no mundo do trabalho via seleção de pessoas.

Nessa perspectiva, interessa-nos destacar ainda a importância das teorias da linguística moderna que trabalha com as noções de variação e mudança, trazendo novos estudos sobre a língua e procurando, a partir deles, demonstrar que a língua "[...] é intrinsecamente heterogênea, múltipla, variável, instável e está sempre em desconstrução e em reconstrução." (BAGNO, 2007, p. 36, grifos do autor).

Vale acrescentar que a heterogeneidade da língua se encontra estreitamente ligada à heterogeneidade social, sendo que 0 fator social de maior impacto sobre a variação linguística é o grau de escolarização que, por sua vez, está, na maioria dos casos brasileiros, ligado diretamente ao status social do falante. 
São esses conceitos que podem viabilizar um olhar diferente, não excludente, para a língua e, consequentemente, seus falantes, independente da classe social a que pertençam.

\section{REFERÊNCIAS}

ANGELONI, Maria Terezinha. Comunicação nas organizações da era do conhecimento. São Paulo: Atlas, 2010.

BAGNO, Marcos. Nada na língua é por acaso: por uma pedagogia da variação linguística. São Paulo: Parábola Editorial, 2007.

Preconceito Linguístico: o que é, como se faz. São Paulo: Loyola, 2003.

BAKHTIN, Mikhail. Marxismo e Filosofia da Linguagem. São Paulo: Hucitec, 2010.

BRASIL. Ministério da Educação. Parâmetros Curriculares Nacionais para o Ensino Médio. Brasília, DF, 1997. Disponível em: <http://portal.mec.gov.br/seb/arquivos/pdf/lingu agens02.pdf>. Acesso em março de 2012.

CAMARA JUNIOR, Joaquim Mattoso. Dicionário de linguística e gramática: referente à língua portuguesa. Petrópolis, RJ: Vozes, 2009.

CORIAT, Benjamin. Pensar pelo avesso: 0 modelo japonês de trabalho e organização. Rio de Janeiro: Revan, UFRJ, 1994.

FERREIRA, Ana Elisa Moreira; SILVA, Vivian Oliveira dos Santos. Fonoaudiologia empresarial: porque seu Call-Center necessita desse enfoque? [S. I.: s. n.], 2002. Disponível em:<http://www.univoz.com.br/shop/shop.dll/im primiraea2.html?Codigo=26>. Acesso em: 1 jul. 2011.

FORD, Henry. Minha Vida e Minha Obra. Rio de Janeiro: Brand, 1954.

LEITE, Márcia de Paula. Trabalho e sociedade em transformação: mudanças produtivas e atores sociais. São Paulo: Fundação Perseu Abramo, 2003.

ORLANDI, Eni. As formas do silêncio. Campinas, SP: Ed. Unicamp, 1992.

POSSENTI, Sírio. Por que (não) ensinar gramática na escola. Campinas, SP: Mercado de Letras: Associação de Leitura do Brasil, 1996.

SAUSSURE, Ferdinand de. Curso de Linguística Geral. São Paulo: Cultrix, 2006.

SOARES, Magda. Linguagem e escola: uma perspectiva social. São Paulo: Ática, 2008.

TAYLOR, Frederick Winslow. Princípios de administração científica. São Paulo: Atlas, 2009.

TRAVAGLIA, Luiz Carlos. Gramática e interação: uma proposta para o ensino de gramática. São Paulo: Cortez, 2009.

\section{NOTAS}

1 "A norma culta é o conjunto de variedades linguísticas efetivamente empregadas pelos falantes urbanos, mais escolarizados e de maior renda econômica." (BAGNO, 2007, p. 117).

2 Em nosso estudo, como já dito, denominamos selecionador o profissional responsável pelo processo de seleção de candidatos a vagas de emprego nas diferentes empresas, lócus da pesquisa.

3 Dados retirados da entrevista S7 com profissional da empresa de médio porte.

4 Dados retirados da entrevista S4 com profissional da empresa de grande porte.

${ }^{5}$ Discurso - toda atividade comunicativa de um locutor, numa situação de comunicação determinada, englobando não só o conjunto de enunciados por ele produzidos em tal situação como também o evento de sua enunciação (TRAVAGLIA, 2009).

6 Dados retirados da entrevista $\mathrm{S} 1 \mathrm{com}$ profissional da empresa de grande porte.

7 Dados retirados da entrevista $\$ 9$ com profissional da empresa de médio porte. 
${ }^{8}$ Dados retirados da entrevista S3 com profissional da empresa de grande porte.

9 Dados retirados da entrevista S4 com profissional da empresa de grande porte.

10 Dados retirados da entrevista S7 com profissional da empresa de grande porte.

11 Dados retirados da entrevista S3 com profissional da empresa de grande porte.

12 Dados retirados da entrevista S2 com profissional da empresa de grande porte.

13 Dados retirados da entrevista S8 com profissional da empresa de médio porte.

14 "Metalinguagem é a propriedade que a língua tem de voltar-se para si mesma, não designando 'coisas', mas a si própria. Dicionários e gramáticas são textos metalinguísticos por excelência" (BRASIL,1997, p. 49 , grifo do autor).

15 "[...] a gramática é concebida como um manual com regras de bom uso da língua a serem seguidas por aqueles que querem se expressar adequadamente." (TRAVAGLIA, 2009, p. 24)

16 Dados retirados da entrevista com profissional da empresa de médio porte.

17 Dados retirados da entrevista com profissional da empresa de grande porte.

18 Dados retirados da entrevista S6 com profissional da empresa de pequeno porte.

19 Dados retirados da entrevista S10 com profissional da empresa de médio porte.

20 Dados retirados da entrevista S11 com profissional da empresa de pequeno porte.

${ }^{21}$ Dados retirados da entrevista S5 com profissional da empresa de grande porte.

22 Dados retirados da entrevista $\mathrm{S} 9$ com profissional da empresa de pequeno porte.

${ }^{23}$ Dados retirados da entrevista $\mathrm{S} 6$ com profissional da empresa de pequeno porte.

${ }^{24}$ Dados retirados da entrevista S8 com profissional da empresa de médio porte.

\section{Eneida Maria Erre Araújo}

Graduada em Letras

Mestra em Educação pela Universidade Federal do Maranhão (UFMA)

Integrante do Grupo de Pesquisa Políticas e Práticas de Formação Profissional (PRAFORP), da Linha de

Pesquisa: Estado e Gestão Educacional do Mestrado em

Educação da UFMA

E-mail: ema.erre@hotmail.com

\section{Ilzeni Silva Dias}

Pedagoga

Doutora em Educação pela Universidade de São Paulo

(USP)

Professora pesquisadora no Programa de Pós-

Graduação Mestrado em Educação da Universidade

Federal do Maranhão (UFMA)

E-mail: ilzedias@hotmail.com

\section{Universidade Federal do Maranhão - UFMA}

Cidade Universitária, Av. dos Portugueses, 1966,

Bacanga, São Luís/MA

CEP: 65080-805 